\title{
PERBANDINGAN ANALISIS FINANSIAL USAHATANI HORTIKULTURA MENGGUNAKAN PUPUK BIOCOCOTIN DAN PUPUK KANDANG PADA LAHAN PASIR DI PROVINSI BENGKULU
}

\author{
Ridha Rizki Novanda*, Anandyawati, Merlian Zikri, Eko Sumartono, \\ Amir Husaini \\ Program Studi Agribisnis, Jurusan Sosial Ekonomi Pertanian \\ Fakultas Pertanian, Universitas Bengkulu, Bengkulu \\ Kontak penulis: rrizkin@unib.ac.id
}

\begin{abstract}
Biococotin is a fertilizer made from human feces and dried cocopit. The use of dried human feces and cocopit can be carried out on sandy land. This is because human feces are one of the feces that have good soil nutrient ability. Can be used as fertilizer on sandy land. Good plant nutrition will correlate with crop yields and farmer's income. Biococotin with manure has been used by farmers. Research carried out on sand farm farmers in Bengkulu Province discussed Lempuing Village, Bengkulu. The study was conducted for one month, June-July 2018. The process of collecting data was obtained from experimental results and interviews. Financial amount of funds needed to build and then carry out business activities. The results obtained from the costs incurred by biococtin are greater than those with manure. The entire competition meets eligibility, but nothing is feasible. This is due to high operational costs. The biggest outpouring of costs is the purchase of dry cocopit. This is because there is no dry cocopit in Bengkulu. The purchase of cocopit is carried out beyond the Bengkulu area at high prices.
\end{abstract}

Keywords: Biococotin, Finansial; Bengkulu.

\begin{abstract}
ABSTRAK
Biococotin salah satu pupuk yang terbuat dari tinja manusia dan cocopit kering. Pemanfaatan tinja manusia kering dan cocopit dapat dilakukan di lahan berpasir. Ini karena tinja manusia merupakan kotoran yang memiliki kemampuan nutrisi tanah yang baik. Nutrisi tanaman yang baik akan berkorelasi dengan hasil tanaman dan pendapatan petani. Sehingga perlu dianalisis bagaimana perbandingan pendapatan pupuk biococotin dengan pupuk kandang yang selama ini digunakan oleh petani. Penelitian dilakukan pada petani lahan pasir di Provisi Bengkulu tepatnya Desa Lempuing, Bengkulu. Penelitian dilakukan selama satu bulan yaitu bulan juni-juli 2018. Proses pengumpulan data di dapatkan dari hasil eksperimaental dan wawancara. analisiss data aspek finansial (keuangan), jumlah dana yang dibutuhkan untuk membangun dan kemudian mengoperasikan kegiatan bisnis. Hasil yang di dapatkan yaitu biaya yang dikeluarkan biococtin lebih besar dibanding dengan pupuk kandang. Keseluruhan komoditas memenuhi kelayakan, akan tetapi komoditas kangkung perlakuan biococotin tidak layak. Hal ini disebabkan karna biaya operasional yang tingi. Curahan biaya paling besar yaitu dalam pembelian cocopit kering. Hal ini dikarenakan tidak tersedianya cocopit kering didaerah Bengkulu. Sehingga pembelian cocopit dilakukan diluar daerah Bengkulu dengan harga mahal.
\end{abstract}

Kata kunci: Biococotin, Finansial, Bengkulu. 
Sitasi: Ridha Rizki Novanda*, Anandywati, Merlian Zikri, Eko Sumartono, Amir Husaini, 2019. Perbandingan Analisis Finansial Ushatani Hortikultura Menggunakan Pupuk Biococotin dan Pupuk Kandang pada Lahan Pasir di Provinsi Bengkulu, JSEP 15(2): 164 - 171

\section{Pendahuluan}

Kota Bengkulu merupakan salah satu kota yang berada di garis pantai terpanjang di Indonesia. Suhu wilayah relatif tinggi karena luasnya wilayah pantai dan karena itu sistem pertanian hortikultura jarang diterapkan di daerah ini. Di kawasan Bengkulu terdapat lahan pasir yang termarjinalkan dan tidak dimanfaatkan. Lahan tersebut pada dasarnya memiliki potensi budidaya hortikultura. Dalam kondisi lahan pertanian padi sawah dan kebun hortikultural pada dataran rendah dan dataran tinggi menghadap berbagai tantangan seperti perubahan iklim (Kamaluddin et.al, 2012) bahkan dampak eksploitasi tambang (Meisanti et.al, 2012) lahan marjinal di pinggir pantai perlu digali potensinya sebagai media tumbuh tanaman pangan.

Potensi lahan pasir sebagai media budidaya hortikultura telah banyak diterapkan pada berbagai daerah. Berdasarkan penelitian Saparso et al. (2009), tanaman hortikultura kubis dapat tumbuh denngan baik pada lahan pasir baik saat musim kemarau maupun saat musim penghujan. Penanaman pantai berpasir dengan tanaman hortikultura dimaksudkan untuk menciptakan iklim mikro yang baik dan juga untuk membuat lingkungan yang indah dan sejuk (Harjadi dan Oktavia, 2008). Kondisi tersebut memungkinkan Bengkulu sangat potensial memanfaatkan lahan pasir untuk budidaya hortikultura. Saat ini di kawasan Desa Lempuing, Kecamatan Sungai Serut, Kabupaten Bengkulu Kota sudah delakukan budidaya hortikultura tanaman sawi, kangkung, bayam dan kucai di lahan pasir.

Berdasarkan sifat fisik tanah pada lahan kering berpasir berpotensi menurunkan pertumbuhan dan perkembangan tanaman yang dibudidaya apabila tidak dilakukan upaya perbaikan tanah. Tidak semua tanaman dapat dibudidaya pada tanah lahan berpasir disebabkan banyaknya kendala yang dijumpai pada lahan kering berpasir sebagai lahan budidaya (Fuady dan Mustaqim, 2015). Kondisi tersebut dialami oleh petani sehingga diperlukan nutrisi tanaman yang memiliki potensi memperbaiki lahan. Saat ini petani di kawasan Desa Lempuing cenderung masih menggunakan pupuk kandang kotoran ayam.

Dalam kondisi lahan pasir pantai yang miskin unsur hara, sebaiknya petani melakukan pembenahan tanah dengan menambah penggunaan pupuk organic, sehingga diharapkan dapat membantu meningkatkan produksi (Istiyani et al, 2015). Biococotin adalah salah satu pupuk yang terbuat dari tinja manusia dan cocopit kering. Pemanfaatan tinja manusia kering dan cocopit dapat dilakukan di lahan berpasir. Cocopit telah diteliti dan terbukti dapat menjadi media dalam pembibitan cempaka (Irawan dan Hidayah, 2014), media tumbuh sengon laut (Ramadha, et.al, 2018, serta dalam pertumbuhaan dua Dipterocarps seedlings (Marjenah et.al, 2016). Hal ini dikarenakan tinja manusia merupakan salah satu kotoran yang memiliki kemampuan nutrisi tanah yang baik sehingga dapat dimanfaatkan sebagai pupuk 
pada lahan berpasir. Nutrisi tanaman yang baik akan berkorelasi dengan hasil tanaman dan pendapatan petani. Sehingga perlu dianalisis bagaimana perbandingan pendapatan pupuk biococotin dengan pupuk kandang yang selama ini digunakan oleh petani.

\section{Metode Penelitian}

Penelitian ini dilakukan pada petani lahan pasir di Provisi Bengkulu tepatnya Desa Lempuing, Bengkulu. Data yang digunakan ialah data primer dan data sekunder. Data primer merupakan data lapangan yang di dapatkan secara langsung yaitu data curahan biaya, penerimaan serta pendapatan dari hasil eksperimental dan wawancara. Sedangkan data sekunder didapatkan dari dari berbagai dokumen dan studi literatur. Penelitian dilakukan selama satu bulan yaitu bulan Juni-Juli 2018. Proses pengumpulan data didapatkan dari hasil eksperimental dan wawancara petani untuk membandingkan bagaimana analisis ekonomi penggunaan pupuk kandang dan pupuk biococotin.

Analisis data dilakukan dengan tabulasi data pengamatan dan kuesioner. Dalam pengkajian aspek finansial (keuangan), dihitung jumlah dana yang dibutuhkan untuk membangun dan kemudian mengoperasikan kegiatan bisnis. Analisis finansial membandingkan kriteria ekonomi setiap komoditas yang dioperasikan melalui kegiatan penelitian dan kebiasaan petani. Penjabaran mengenai kriteria pengukuran ekonomi adalah sebagai berikut.

\section{Biaya yang Dikeluarkan}

Biaya yang dikeluarkan dianalisis berdasarkan satuan per hektar maupun per musim panen dan per luas lahan dari petani di daerah tersebut. Biaya yang dikeluarkan meliputi pembelian alat investasi, biaya tetap, biaya variabel, dan biaya lainnya.

\section{Penerimaan Kotor}

Penerimaan kotor merupakan hasil penjualan yang dilakukan dengan asumsi keseluruhan hasil penen laku terjual pada penelitian ini. Penerimaan kotor memiliki nilai yang berbeda-beda di setiap jenis komoditas karena harga jual dan bobot yang dihasilkan berbeda.

\section{Penerimaan Bersih}

Total penerimaan bersih didapatkan dari nilai penjualan maupun curahaan biaya yang dikeluarkan. Nilai penerimaan bersih dihitung berdasarkan satuan per hektar maupun per musim panen dan per luas lahan dari petani di daerah tersebut.

\section{Net Present Value (NPV)}

Suatu bisnis dinyatakan layak bila seluruh manfaat yang diterimanya melebihi biaya yang dikeluarkan. Selisih antara manfaat dan biaya disebut dengan manfaat bersih atau arus kas bersih. Suatu bisnis dinyatakan layak jika NPV lebih besar dari nol. 


$$
N P V=\sum_{t=0 / 1}^{n} \frac{\mathrm{Bt}-\mathrm{Ct}}{(1+\mathrm{i})^{\mathrm{t}}}
$$

Keterangan: $\mathrm{Bt}=$ Manfaat pada tahun $\mathrm{t}$

$\mathrm{Ct}=$ Biaya Pada Tahun $\mathrm{t}$

$\mathrm{T}=$ tahun kegiatan bisnis

i $\quad=$ Tingkat DR (\%)

Kriteria kelayakan : $\quad$ NPV $>0$ Usahatani layak untuk diusahakan

NPV $<0$ Usahatani tidak layak untuk diusahakan

Gross Benefit-Cost Ratio (Gross B/C)

Analisis Gross Benefit Cost Ratio (Gross B/C Ratio) merupakan kriteria kelayakan lain yang biasanya digunakan dalam analisis bisnis. Dengan kriteria ini akan lebih menggambarkan pengaruh dari adanya tambahan biaya terhadap tambahan manfaat yang diterima. Dilakukan pula perhitungan Gross Benefit agar dapat mengetahui pengaruh dari adanya tambahan biaya terhdap tambahan manfaat yang diterima dalam bisnis tersebut. Kriteria layak apabila Gross B/C lebih besar dari satu dan bisnis tidak layak bila Gross B/C kurang dari satu.

$$
\operatorname{Gross} \frac{B}{C}=\sum_{t=0 / 1}^{n} \frac{\frac{B t}{(1-i)^{t}}}{\frac{C t}{(1-i)^{t}}}
$$

$$
\text { Keterangan : } \quad \begin{array}{ll}
\mathrm{Bt} & =\text { Manfaat pada tahun } \mathrm{t} \\
\mathrm{Ct} & =\text { Biaya Pada Tahun } \mathrm{t} \\
\mathrm{t} & =\text { tahun kegiatan bisnis } \\
\mathrm{i} & =\text { Tingkat DR }(\%) \\
\frac{1}{(1+i)^{t}} & =\text { Discount Factor (DF) pada tahun ke-t }
\end{array}
$$

Kriteria kelayakan: Gross B/C $>1$ Usahatani layak untuk diusahakan

Gross B/C $<1$ Usahatani tidak layak untuk diusahakan

\section{Hasil dan Pembahasan}

\section{Biaya Produksi}

Biaya yang dikeluarkan dianalisis berdasarkan satuan per hektar maupun per musim panen dan per luas lahan dari petani di daerah tersebut. Biaya yang dikeluarkan meliputi pembelian alat investasi, biaya tetap, biaya variabel, dan biaya lainnya. 
Tabel 1

Rata-rata Biaya Produksi.

\begin{tabular}{lcccccc}
\hline \multirow{2}{*}{$\begin{array}{c}\text { Jenis } \\
\text { sayuran }\end{array}$} & \multicolumn{2}{c}{ Biaya Produksi Rp/ha } & \multicolumn{2}{c}{$\begin{array}{c}\text { Biaya Produks Rpi/ha/musim } \\
\text { panen }\end{array}$} & \multicolumn{2}{c}{$\begin{array}{c}\text { Biaya produksi Rp/ha/musim } \\
\text { panen/lahan petani }\end{array}$} \\
\cline { 2 - 7 } & $\begin{array}{c}\text { Pupuk } \\
\text { kandang }\end{array}$ & Biococotin & $\begin{array}{c}\text { Pupuk } \\
\text { kandang }\end{array}$ & Biococotin & $\begin{array}{c}\text { Pupuk } \\
\text { kandang }\end{array}$ & Biococotin \\
\hline Sawi & 273.892 .360 & 392.521 .030 & 45.648 .727 & 65.420 .172 & 365.190 & 523.361 \\
Kucai & 189.318 .100 & 373.380 .850 & 31.553 .017 & 62.230 .142 & 252.424 & 497.841 \\
Kangkung & 184.373 .052 & 384.428 .050 & $30.728,842$ & 64.071 .342 & 245.831 & 512.571 \\
Bayam & 181.741 .504 & 390.060 .952 & 30.290 .251 & 65.010 .159 & 242.322 & 520.081 \\
\hline
\end{tabular}

Berdasarkan hasil analisis didapatkan bahwa biaya rata-rata yang dikeluarkan paling besar pada komoditas sawi dan paling rendah pada komoditas bayam (menggunakan pupuk kandang) serta komoditas kucai (menggunakan pupuk biococotin). Curahan biaya paling besar ialah pada biaya operasional yaitu pembelian pupuk. Besarnya biaya pembelian pupuk mencapai 63\%-71.8\%dari total biaya produksi setiap tahunnya.

Berdasarkan hasil analisis pada Tabel-1, didapatkan bahwa biaya menggunakan pupuk biococotin cenderung lebih besar dibandingkan biaya menggunakan pupuk kandang. Hal ini disebabkan karena harga pupuk dari biococotin lebih tinggi dibandingkan pupuk kandang yang digunakan oleh petani. Nilai pupuk kandang ialah 53\% lebih kecil dibandingkan dengan pupuk biococotin. Hal ini menyebabkan biaya produksi peneliti lebih besar.

\section{Penerimaan Kotor}

Penerimaan kotor merupakan hasil penjualan yang dilakukan dengan asumsi keseluruhan hasil panen laku terjual pada penelitian ini. Penerimaan kotor memiliki nilai yang berbeda-beda di setiap jenis komoditas karena harga jual dan bobot yang dihasilkan berbeda.

Tabel 2

Penerimaan Kotor.

\begin{tabular}{lcccccc}
\hline \multirow{2}{*}{$\begin{array}{c}\text { Jenis } \\
\text { sayuran }\end{array}$} & \multicolumn{2}{c}{ Penerimaan Kotor Rp/ha } & \multicolumn{2}{c}{$\begin{array}{c}\text { Penerimaan Kotor } \\
\text { Rp/ha/musim panen }\end{array}$} & \multicolumn{2}{c}{$\begin{array}{c}\text { Penerimaan Kotor Rp/ha/musim } \\
\text { panen/luas lahan }\end{array}$} \\
\cline { 2 - 7 } & $\begin{array}{c}\text { Pupuk } \\
\text { kandang }\end{array}$ & Biococotin & $\begin{array}{c}\text { Pupuk } \\
\text { kandang }\end{array}$ & Biococotin & Pupuk kandang & Biococotin \\
\hline Sawi & $548.326, .00$ & 701.920 .912 & 91.387 .800 & 116.986 .819 & 731.102 & 935.895 \\
Kucai & 468.180 .000 & 652.860 .000 & 78.030 .000 & 108.810 .000 & 624.240 & 870.480 \\
Kangkung & 199.260 .000 & 234.090 .000 & 33.210 .000 & 39.015 .000 & 265.680 & 312.120 \\
Bayam & 307.800 .000 & 532.800 .000 & 51.300 .000 & 88.800 .000 & 410.400 & 710.400 \\
\hline
\end{tabular}

Berdasarkan hasil analisis yang didapatkan, penerimaan kotor paling besar ialah pada komoditas sawi dengan curahan penerimaan lebih tinggi dibandingkan lainnya. Sedangkan komoditas yang memiliki penerimaan kotor paling rendah ialah kangkung. Hal ini dikarenakan hasil penjualan kangkung dan harga jual lebih rendah. 
Penerimaan kotor perlakuan biococotin lebih besar dibanding perlakuan dari pupuk kandang. Dengan harga jual yang sama, akan tetapi kuantitas hasil menggunakan pupuk biococitin jauh lebih besar dibandingkan dengan pupuk kandang. Bobot produksi perbatang perlakuan biococotin lebih besar dibandingkan dengan perlakuan pupuk kandang.

\section{Pendapatan}

Total pendapatan bersih didapatkan dari nilai penjualan maupun curahaan biaya yang dikeluarkan. Nilai pendapaatan bersih dihitung berdasarkan satuan per hektar maupun per musim panen dan per luas lahan dari petani di daerah tersebut.

Berdasarkan hasil analisis didapatkan bahwa rata-rata penerimaan bersih paling besar didapatkan dari komoditas kucai dan rata-rata penerimaan bersih paling rendah didapatkan pada komoditas kangkung (perlakuan pupuk kandang) serta komoditas bayam (perlakukan pupuk biococotin). Besarnya nilai rata-rata pendapataan bersih sangat bergantung pada besarnya biaya yang dikeluarkan dan besarnya penerimaan yang didapatkan (Tabel-3).

Tabel 3

Rata-rata Pendapatan Bersih.

\begin{tabular}{|c|c|c|c|c|c|c|}
\hline \multirow[t]{2}{*}{$\begin{array}{l}\text { Jenis } \\
\text { sayuran }\end{array}$} & \multicolumn{2}{|c|}{$\begin{array}{l}\text { Rata-rata pendapatan } \\
\text { bersih } R p / \text { tahun }\end{array}$} & \multicolumn{2}{|c|}{$\begin{array}{l}\text { Rata-rata pendapatan bersih } \\
\text { Rp/musim panen }\end{array}$} & \multicolumn{2}{|c|}{$\begin{array}{c}\text { Rata-rata pendapatan } \\
\text { bersih } \mathrm{R} / \mathrm{musim} \\
\text { panen/luas lahan } \\
\text { petani }\end{array}$} \\
\hline & $\begin{array}{c}\text { Pupuk } \\
\text { kandang }\end{array}$ & Biococotin & $\begin{array}{c}\text { Pupuk } \\
\text { kandang }\end{array}$ & Biococotin & $\begin{array}{c}\text { Pupuk } \\
\text { kandang }\end{array}$ & Biococotin \\
\hline Sawi & 237.583 .592 & 140.384 .182 & 39.597 .265 & 23.397.364 & 316.778 & 187.179 \\
\hline Kucai & 241.415 .680 & 241.95 .783 & 40.235 .947 & 40.325 .297 & 321.888 & 322.602 \\
\hline Kangkung & 12.842 .630 & - 130.224.925 & 2.140 .438 & 21.704 .154 & 17.124 & -173.633 \\
\hline Bayam & 109.105 .554 & 123.549 .166 & 18.184 .259 & 20.591 .528 & 145.474 & 164.732 \\
\hline
\end{tabular}

Curahan pendapatan komoditas sawi perlakukan pupuk kandang lebih besar dibanding dengan perlakuan pupuk biococotin. Hal ini dikarenakan tingginya biaya produksi yang dikeluarkan oleh perlakuan pupuk biococotin tidak berbanding seimbang dengan perlakuan pupuk kandang. Berbeda dengan kucai dan kangkung, perlakuan pupuk biococotin lebih besar mendapatkan pendapatan bersih dibandingkan dengan perlakuan pupuk kandang. Bayam memiliki rata-rata pendapatan bersih perlakuan pupuk biococotin lebih besar dibandingkan dengan dengan perlakuan pupuk kandang.

\section{Net Present Value (NPV)}

Suatu bisnis dinyatakan layak bila seluruh manfaat yang diterimanya melebihi biaya yang dikeluarkan. Selisih antara manfaat dan biaya disebut dengan manfaat bersih atau arus kas bersih. Suatu bisnis dinyatakan layak jika NPV lebih besar dari nol.

Berdasarkan hasil analisis pada Tabel-4, mayoritas komoditas dengan kedua perlakuan berada pada nilai di atas dari nol. Hal ini menunjukkan bahwa usahatani 
mengalami keuntungan, tetapi komoditas kangkung perlakuan peneliti memiliki nilai NPV negatif. Kondisi demikian menunjukkan bahwa komoditas kangkung menggunakan pupuk biococotin tidak layak diusahanaan akibat tingginya biaya produksi yang tidak berbanding lurus dengan penerimaan.

Tabel 4

NPV.

\begin{tabular}{lrr}
\hline \multirow{2}{*}{ Jenis sayuran } & \multicolumn{2}{c}{ NPV } \\
\cline { 2 - 3 } & Pupuk kandang & \multicolumn{1}{c}{ Biococotin } \\
\hline Sawi & 1187917959 & 701920911.6 \\
Kucai & 1207078400 & 1209758914 \\
Kangkung & 64213147.67 & -651124626.4 \\
Bayam & 545527771.4 & 617745832.1 \\
\hline
\end{tabular}

Gross Benefit-Cost Ratio (Gross B/C)

Analisis Gross Benefit Cost Ratio (Gross B/C Ratio) merupakan kriteria kelayakan lain yang biasanya digunakan dalam analisis bisnis. Dengan kriteria ini akan lebih menggambarkan pengaruh dari adanya tambahan biaya terhadap tambahan manfaat yang diterima. Dilakukan pula perhitungan Gross Benefit agar dapat mengetahui pengaruh dari adanya tambahan biaya terhadap tambahan manfaat yang diterima dalam bisnis tersebut. Kriteria layak apabila Gross B/C lebih besar dari 1 dan bisnis tidak layak bila Gross B/C kurang dari 1.

Tabel-5

Gross B/C.

\begin{tabular}{lrr}
\multicolumn{3}{c}{ Gross B/C. } \\
\hline \multirow{2}{*}{ Jenis sayuran } & \multicolumn{2}{c}{ Gross B/C } \\
\cline { 2 - 3 } & Pupuk kandang & Biococotin \\
\hline Sawi & 2.00 & 1.41 \\
Kucai & 2.47 & 1.75 \\
Kangkung & 1.08 & 0.61 \\
Bayam & 1.69 & 1.37 \\
\hline
\end{tabular}

Berdasarkan hasil analisis didapatkan bahwa mayoritas komoditas dengan kedua perlakuan berada pada nilai di atas dari satu. Hal ini menunjukkan bahwa usahatani mengalami keuntungan. Akan tetapi komoditas kangkung perlakuan pupuk biococotin memiliki nilai Gross B/C dibawah satu. Kondisi demikian menunjukkan bahwa komoditas kangkung menggunakan pupuk biococotin tidak layak diusahakan akibat tingginya biaya produksi.

\section{Kesimpulan}

Berdasarkan hasil dan pembahasan, dapat ditarik kesimpulan bahwa: (1) Biaya yang dikeluarkan pada perlakuan biococotin lebih besar dibanding dengan perlakuan pupuk kandang dengan curahan paling besar yaitu pada pupuk biococotin; (2) Penerimaan kotor perlakuan biococotin lebih besar dibandingkan pupuk kandang, hal ini dikarenakan bobot hasil produksi yang lebih besar; (3) 
Dikarenakan biaya produksi yang besar, rata-rata penerimaan perlakuan biococotin lebih besar dibandingkan pupuk kandang; (4) Keseluruhan komoditas memenuhi kelayakan, akan tetapi komoditas kangkung dengan perlakuan biococotin dinyatakan tidak layak, hal ini disebabkan biaya operasional yang tingi; (5) Biococotin terbuat dari biotin dengan cocopit. Curahan biaya paling besar yaitu dalam pembelian cocopit kering, ini disebabkan tidak tersedianya cocopit kering didaerah Bengkulu, sehingga pembelian cocopit dilakukan diluar daerah Bengkulu dengan harga yang relatif mahal. Alternative terbaik ialah membuat cocopit sendiri, akan tetapi pengolahannya relatif lama dan membutuhkan tenaga yang banyak karena bergantung dengan iklim.

\section{Daftar Pustaka}

Fuady, Z. dan Mustaqim, 2015. Pengaruh Olah Tanah Terhadap Sifat Fisika Tanah Pada Lahan Kering Berpasir. Jurnal Lentera, Vol. 15, No. 15: 12-22.

Harjadi, B. dan D. Oktavia, 2008. Penerapan Teknik Konservasi Tanah di Pantai Berpasir untuk Agrowisata. Info Hutan, Vol. 5, No. 2: 113-121.

Irawan, A. dan H. Nurul, 2014. Kesesuaian Penggunaan Cocopeat sebagai media Sapih pada Politube dalam Pembibitan Cempaka (Magnolia elegans (Blume) H. Keng Seddlings). Jurnal Wasian, Vol.1, No.2: 73-76.

Istiyanti E, U. Khasanah dan A. Anjarwati, 2015. Pengembangan Usahatani Cabai Merah di lahan Pasir Pantai Kecamatan Temon Kabupaten Kulonprogo. Agraris, Vol.1, No.1: 6-11.

Kamaluddin, A., A. Ala, MSS. Ali, D. Salman, 2012. "The Adaptation of Rice Paddy Farmers Towards Climate Change". American-Eurasian Journal of Agricultural and Environmental Science. 12 (7).

Marjennah, Kiswanto, S. Purwanti, F.P.M. Sofyan, 2016. The Effect of Biochar, Cocopeat and Sawdust Compost on the Growth of Two Dipterocarps Seedlings. Nusantara Bioscience, Vol.8, No.1: 39-44.

Meisanti, K. Jusoff, D. Salman, D. Rukmana, 2012. “The Impacts of Gold Mining on the Farmers Community". American Journal of Sustainable Agriculture, 6: 209-214.

Ramadhan, D., M. Riniarti dan T.Santoso, 2018. Pemanfaatan Cocopeat sebagai Media Tumbuh Sengon Laut (Paraserianthes falcataria) dan Merbau Darat (Intsia palembanica). Jurnal Sylvia Lestari, Vol.6, No. 2:22-30.

Saparso, Tohari, Shiddieq dan Setiadi, 2009. Anasir Lingkungan Penentu Produksi Kubis di Lahan Pasir Pantai. J.Hort, Vol.19, No. 3: 301-312. 